\section{Merlin Stone}

is a leading expert in customer management and change management in marketing, sales and service. He is a visiting

Professor at De Montfort, Oxford

Brookes and Portsmouth

Universities. He also teaches

economics and develops

advanced economics teaching material for the Open University.

He has published over a hundred academic articles and more than 30 books, as well as countless trade press articles.
Keywords: digital marketing, direct marketing, training, testing, the IDM

\title{
Opinion Piece
}

\section{Building digital skills through training}

\author{
Merlin Stone
}

\begin{abstract}
A dual market exists for training - digital marketers who need to grasp the full breadth of both online and offline activity and conventional marketers who need to skill-up for the digital realm. This article considers the differing needs of these groups and how well existing training resources are meeting them.

Journal of Direct, Data and Digital Marketing Practice (2014) 16, 3-14. doi:10.1057/dddmp.2014.44
\end{abstract}

\section{A revolution in how we market}

In the last few months, the Institute of Direct and Digital Marketing, of which I am an Honorary Life Fellow, has asked me to help with several digital marketing training programmes. It reminds me of when, 30 years ago, the demand for direct marketing training was surging, as big companies (some recently privatized, such as BT, British Gas and BA) implemented customer databases for the first time. They discovered how responsive customers were to relevant communications, but also that they needed to change the mindsets, knowledge and skills of large numbers of their people, at all levels. These people came from many backgrounds, including advertising, public relations, retailing, brand and product management, general and technical sales, telemarketing and, of course, customer service. A revolution had taken place in what they could do. A parallel revolution had to take place in what they were trained, able and motivated to do.

This revolution then spread out by sector, as various market changes (privatization, deregulation and a general collapse of barriers to competition) forced companies to become much more professional in how they managed their customers. The skills also spread, with the industries that were strongest in direct marketing (eg, mail order, credit cards) losing some of their best people to industries that were desperate for their skills (eg, telecommunications, insurance, travel, utilities and, eventually, retailing).

Today, a similar revolution in marketing, sales and service is taking

\section{Offline still delivering most revenue}

Merlin Stone Consulting 1, Broadmead Close, Hampton, Middlesex TW12 3RT, UK.

E-mail: merlin@merlin-stone.com place because of the growth of digital capabilities and their addition to and in some cases substitution for - older ways of doing business.

Therefore, companies face the same challenges they faced 30 years ago, as they wrestle with the continuous growth in channels, media, consumer touch-points and marketing technology. However, in many companies, 
Digital is not a bolt-on

\section{Lack of a direct marketing background}

\section{The distraction of technology}

\section{Training in established disciplines}

\section{Holding on to the past}

offline ways of doing business (including direct marketing) still deliver most revenue and profit. This means digital (at least for the moment) must take its place alongside them.

However, while digital techniques are becoming a key for success, for most companies the link between online and offline marketing is critical, as is the need to manage a combination of online and offline channels. Most customers do not separate their online and offline lives - they tend to mix these journeys. The few leading-edge companies that have a data management platform that combines the two sets of data have realized that they need skills and knowledge from both online and offline worlds in order to manage and use the data. A view that is either purely online or offline is a partial view. One issue here is that the new digital capabilities are often 'bolted on' to marketing departments, rather than integrated strategically.

\section{It's not just me!}

Before finalizing this article, I sent a draft to several senior managers who are managing 'across the digital divide' and received so many responses that I had to rewrite most of it. In fact, the article tripled in length. I am really grateful to all those who took the time (see Acknowledgements).

In my training work, I've discovered that only a few of those working in digital areas have solid backgrounds in direct marketing, or indeed in older (and still current) forms of offline marketing, where the disciplines of targeting, segmentation, relevance, return on investment and the like are firmly established. Many others have been drawn into the digital arena because of their competence and interest in digital techniques for engaging customers and conducting business, but do not have a background in offline marketing.

This creates a problem, particularly for clients with both online and offline requirements. Marketers who are 'digital natives' - purely digital in terms of their training and experience - are unfamiliar with the techniques and measures required to deliver offline results from online activities, or vice versa. One of those who commented on this article felt that it might be harder for digital natives to learn the skills of traditional marketing and not be distracted by 'cool stuff' than for digital non-natives to re-apply their marketing toolbox to new channels. This applies not just at the technique level, but also to big ideas and big insights, in particular the risk of failing to apply new insights to create market-disrupting re-positioning, because of the distraction of technology and distribution

Most young digital marketers that I train are unfamiliar with more basic or earlier marketing disciplines, but do need at least some familiarity, particularly when their work is competitive with or complementary to approaches based on these disciplines (many of which are still very powerful and evolving). Therefore, I have learnt to factor into my training work rapid coverage of these disciplines, while retaining a strong digital focus.

One respondent said that he is seeing a new generation of excitable digital talent that is a little naïve in terms of knowing what is effective and efficient. He said that they tended to lean on relatively new methods like digital attribution, which often carries with it the assumption that the 
buying experience is composed of a narrow online sequence of events. As he pointed out, many, if not most, buying decisions are not managed purely through digital touch points and assuming so leads to biased outcomes and imbalanced judgements. However, he also pointed out that offline marketers are guilty of holding onto the past, using traditional ideas like placing phone numbers and measuring direct response without reference to the digital side.

Investment, insight and training

Accounting for delivery

Volume instead of value

\section{Bridging the gap between specialists}

\section{Targeting, timing, offer and creative}

One respondent stated, "we are facing a big challenge on attribution. We have, at best, two silos of data, one offline and another online, so measuring attribution across these datasets is nigh-on impossible. But even within online, we cannot measure attribution to the degree we want. The cause of this is a lack of investment in appropriate technologies as well as the skills to be able to undertake the analysis we want'. One might suggest that the lack of investment is a result of a lack of insight (foresight), and the lack of insight is a result of a lack of training (awareness).

Another respondent pointed out that it was easy to forget that, when it comes to physical products bought digitally, there was not only the use of the physical product to consider, but the delivery. As we know from Amazon's initial experiments in this area, physical logistics is a challenging area and, for many customers, it is the most important last step (or last-but-one before usage). Excluding it from evaluation is a mistake.

\section{Connecting activity and results}

In some cases, the problem is caused by a marketing director who, as one respondent put it, 'tells his people to make a new digital channel work an invitation to indiscriminate use of the channel to achieve volume instead of value'. Companies (agencies and clients) that understand this risk have developed strong capabilities (usually described as 'evidence', 'measurement' or 'marketing science' capabilities). The people who work there are properly qualified, understand and can measure effectiveness online and offline, using techniques such as econometrics. They ensure that a company becomes more discriminating in its approach and also educate senior decision makers. They are specialists not only in the technical disciplines of evidence, but also in applying them to consumers.

One of my respondents pointed out that, when digital marketing began to emerge, digital marketing agencies were staffed by a combination of 'heavy web techies' and 'alternative creatives', specializing in implementing communications approaches that differed from those used in the offline world. There was no regard for calculating the effectiveness of campaigns. This respondent believed that, even though many of the smaller agencies have been acquired by larger ones, the power is still in the hands of the techies, to some extent alienating the business and professional marketers. The techies need educating in marketing.

He suggested that it is sometimes wrongly believed that that digital techies can do measurement, that they can test design and targeting, because they are 'technical'. This is wrong. Most do not understand the meaning and scope of marketing testing, thinking it is just about creating variations in a website, with no inkling of how to create a set of test cells 


\section{Getting creative with digital discussions}

\section{Direct marketing needs to appreciate digital data}

for the classics of targeting, timing, offer and creative, or even how to create valid test cells and control groups. The latter ie, creative tends to be their main focus. However, even those involved in digital/web analytics may make the error of talking to senior stakeholders about the techniques and methodology, rather than what the analysis can achieve. This same respondent pointed out that it is still tough to find people conversant in data and conventional marketing who can create insights and help translate them into action - and that this shortage is even worse when it comes to digital marketing.

On the other hand, the business/marketing folk need training to build their confidence in managing marketing in the digital world, ensuring basic concepts are understood and schoolboy errors avoided, helping them to understand what questions to ask. Therefore, training certainly has a wide range of roles to play. Some marketers whose work is primarily offline should learn about digital marketing because it is affecting what they do. A good recent example relates to a business-tobusiness key account management training programme I am working on. It was clear that the trainees and their company needed to be much more creative about how to use digital techniques to engage in discussions with their customers about how things were going and what should be done we are working on it.

One of my respondents suggested that a key risk for businesses is the speed of change of digital adoption and the internal ability to keep up. He pointed out that 'better integration of digital capability' is easy to say, but difficult to do. Both areas are under pressure in different ways. Offline is under pressure, for example, because of slow processes and monthly update cycles. Online is under pressure because of, for example, the imperative to 'keep the lights on', constant change and lack of skilled resource. He felt that better appreciation of each area's needs would help and gave the example of appreciating that some data from the unstructured world of digital is required in the structured world of direct marketing data, while those involved in the latter world need to appreciate that some decisions need to be taken instantly.

\section{Wait a minute - What is digital marketing?}

So far, I've used the term digital marketing as if it covered one area. Just as with 'conventional' marketing, there are many digital marketing areas. They include:

- How marketing strategy is affected by the use of digital channels, in particular how the drive to use digital to reduce marketing costs may lead to reduced differentiation, even commoditization and consequent competitive weakness and lower margins and even revenues, and possibly to financial exposure because offline costs remain the same.

- How competitive marketing strategy is affected by the changes digital approaches allow you to make to business models, sometimes providing the ammunition to attack and bring down competitors, as many offline retailers and IT companies have discovered. 
- How to plan digital marketing, covering how to develop and manage new ways of contacting and managing customers.

- How to manage different digital channels (eg, web, mobile, email), overall and in specialist technique areas, eg, search engine optimization, developing and managing apps.

- How to optimize across and within digital channels, including through accurate attribution and smart real-time bidding.

- Managing, analysing and presenting digital data, from developing insight to dashboard management. A key area here is to understand what the data is telling you, in particular staying open-minded about it and using classic market research to find out why the results are as they are.

\section{Digital analytics - An example}

\section{Competitive, not complementary}

\section{Attribution - An example}

The more technical the area, the more rapid the evolution of technique and so the more quickly training material can date, but the greater the possibility of new techniques distracting you from the essentials of competitive marketing.

Let's take digital analytics as an example. The volume of data on customers and products, on channels and supply chains, on campaigns and strategies has exploded exponentially, as it has expanded from the real to the digital world. Making sense of this data to improve everything from what individual customers see and respond to on their (smaller and smaller) screens to the highest-level business strategy is now critical to business success. The development of analytical software and services is racing ahead, to keep up with the demands of managers under pressure to make sense of new, complex, enormous, constantly changing and often fragmented data sets. Great advances have been made, with some companies achieving dramatic returns for their investments. I have seen examples of companies achieving 20-30 per cent reductions in digital budgets while achieving the same returns and increases in returns for individual campaigns of 500 per cent.

However, many companies still find it hard to make sense of data from the real world, while their digital teams work separately to optimize online returns. It is almost as if the two were competitive, rather than complementary. Meanwhile, not only are purely digital skills in short supply, but so are the skills of storytelling with data, influencing skills for analysts, presentation skills, and constructing meaningful infographics and dashboards. A bad management information (MI) dashboard is still a bad MI dashboard, whether it covers digital data or responses to a classic direct marketing campaign. Furthermore, digital marketing analytics is at an early stage of evolution. The statistical sophistication applied to real databases covering tens of channels, hundreds of supply chains, thousands of products, millions of customers and billions of transactions and interactions is often absent from digital analytics.

Here, a good example is attribution analysis - determining which of a series of digital events involving the customer is responsible for the final outcome (usually a sale). Often, the credit is given just to the last click surveys show that around half the companies that use digital marketing use this approach. As I write, the market is moving from arbitrary allocation of weighting to statistically derived weightings based on analysis of actual 


\section{Where buying cycles begin and end}

\section{Shift in digital marketing strategy}

\section{More sophisticated behaviour}

\section{Digital return on investment more complicated}

The new analytics capability customer behaviour. Companies that make this move usually end up discovering that customers are interested in brand, in evaluation, in discovery while they are using sites that were conventionally thought to be final decisions sites (eg, comparison sites or big intermediaries like Amazon). However, many customers consult these sites at the beginning and end of the buying process.

Attribution also covers non-digital channels, although you might think from the coverage given to attribution in blogs and articles that non-digital channels did not exist! As much research shows, many buying cycles start online and end offline, or vice versa. As more companies (clients or agencies) start to use data management platforms covering data from both types of channel, this problem will be resolved.

Attribution models also need some research insight. If several treatments are used at different times, then a purely statistical approach will model which ones a customer is most exposed to. However, a customer's response is positively or adversely affected because they like or dislike what they are being served.

Digital analysis largely thrives on the speed with which it can identify who is doing what, when and how they can be encouraged to do a bit more of what is good or profitable and a bit less of what is bad or unprofitable. However, the strategic trend in digital marketing is away from 'doing unto a consumer' and towards enabling their journey, so digital analysis must reflect this.

One respondent suggested, slightly cynically, that in his sector consumers undertake complex, multi-stage, multi-channel purchase journeys with a good proportion only doing so to gain leverage to haggle with providers (consumers are not all as apathetic as some think), to postrationalize their current provider or to find a way of buying a product more cheaply. Consumers are becoming ever more sophisticated at doing this and companies need to keep up with their behaviour.

A respondent from the same sector suggested that applying analytics to costs and returns is very important. The difference is that, whereas in the 'old world' of direct marketing cost per contact influenced marketing returns heavily, in digital environments the issue is opportunity cost (effectively, the opportunity lost by a failed contact) and investment in creative and advertisement placement costs. As he put it, 'It is becoming more important to understand where your marketing expense is effective and where it is wasted, and the returns it can generate. In many ways, it is more complex than the traditional direct marketing model of cost per contact, response rate and understanding the net present value of a campaign. Placement, relevance, call to action and timeliness become more important in digital marketing, which is where big data and response optimisation come in'.

\section{Converging capabilities}

Real-world and digital marketing analytics are converging to create a capability with the power to transform how a company markets, sells and services. This is via the comprehensiveness and comprehensibility of the 
Scenario planning

\section{What consumers click, not how they tick}

insight it gives, the speed with which it gives it and, in some cases, the automated deployment of its application to actions. My view is that marketers need to be trained to use the different elements of that capability, to understand how they are developing, how they should be deployed, integrated and managed, and - perhaps most importantly of all — how to keep their skills and knowledge updated. They also need to understand particularly if they are working for or supplying services to companies with both online and offline operations and where online generates offline sales how analytics and measurement is applied to all marketing, sales and service, in many ways recreating the classic closed-loop of direct marketing.

At the other end of the digital marketing spectrum - digital marketing strategy and planning - managers need to learn how digital marketing capabilities can transform the effectiveness of existing business models, from how managers understand what is going on and the effects of what they are planning and doing, to how they use measurement to improve effectiveness (changing how they market and sell) and efficiency (improving the benefit/cost ratio of what they do). Managers need to be able to cope with difficult questions, such as:

'How would we track the results of our efforts if cookies were banned or if regulators required consumers to give such a clear re-confirmation when served a cookie that they started not to accept them?' or 'what if regulators, on privacy grounds, tried to find some way of preventing discrimination against consumers who refused to accept cookies?' Other key issues to consider are 'as the world moves most of its dialogue onto mobile apps, how will this affect our work?' and 'what difference do developments in mobile payment, video on demand or locational data make?', or 'if we get a data management platform, how will it change how we work?'

One respondent put all this a little more simply: 'Everyone needs a bit of digital and a bit of non-digital thinking!' Having experts in the digital channel is not ideal, as it can prevent the rounded thinking required to manage across channels. He added that, where customer service and support is concerned, the 'human-free' essence of digital marketing must change. Furthermore, the very strong but not exclusive impact of digital marketing on branding means that integration of digital and non-digital approaches is essential. Another respondent added to this by referring to working with a young 'digital expert' who asked with a faint curl of the lip, 'does anyone actually read direct mail?' Or, as another respondent put it, these digital experts know that consumers click, on what and perhaps how often, but not what makes consumers tick!

\section{What training is needed?}

Not all companies, individuals or departments within companies need the same kind of training. Some need very advanced, up-to-the-minute technique training, others need re-orientation training, focusing on how marketing strategy and planning needs to change in a digital age. Some need training that is purely focused on digital, others need training that is focused on integrating the marketing planning and delivery cycle for online and offline businesses. 


\section{Effect of the recession on resources}

\section{Not possible to learn on the job}

\section{Lack of testing on the syllabus}

Focus on teachability, not applicability
From the individual trainee's point of view, it is important to note that the form in which the training is provided, and whether it is validated, is as important as the content. So let's have a quick look at the providers entirely with bias, given my strong association with the IDM's training! What kind of training should this new generation of marketers have and who should it be provided by?

One respondent commented that the skills problem had been exacerbated by the recession, which increased the need for training as companies needed to use digital marketing more because of its competitiveness and costs. However, the number of graduates hired was cut, along with training budgets. This led to a shortage of people coming through the junior ranks. In some companies, resources are still tight and training may be pushed down the priority list. This is particularly damaging in view of the fact that digital marketing is very technical.

Common sense still helps, but there are now tools, techniques and processes that must be learnt and applied, as well as specific skills that are required. They are not so easy to 'pick up as you go along'. The digital approach has also made marketing more complex. This has resulted in marketing becoming more siloed and marketers becoming more specialized than ever. But marketers need to understand all marketing disciplines in order to manage the journeys of their customers across different digital worlds and between online and offline worlds. It is much less likely that marketers will be able to learn the end-to-end process 'on the job'. Without this understanding of the end-to-end process, it will be hard for them to progress into more strategic roles, and this could lead to boredom and frustration. So training must be promoted up the agenda.

\section{What training is being provided?}

Much conventional training is just a modern version of chalk-and-talk slides and links, telling trainees what they can and should do, and giving them lots of examples. This is not bad for an initial approach, particularly if you want your people to get to grips with a particular framework. However, it is important for trainees to apply what they have learned quite soon. Case study assignments and projects seem to be best for these, but have a critical requirement that the trainers (or others) marking them are in touch with best practice and can critique. Believe me, this can go badly wrong. I came across a situation recently in which a university teaching integrated marketing communications, culminating in a project, had nothing in its syllabus about testing of any element of the marketing communications mix. Can you imagine not testing, particularly in a world where things are changing so quickly and it is never quite clear what will work? Testing and re-testing are a critical requirement. Worse, it was clear that not many of the tutors were up to speed with modern ideas on testing and their statistical foundations.

\section{Can universities help?}

Therefore, who should do the training? Let's start with the universities. Some (though not all) are some years behind the leading edge of digital 


\section{Universities offering relevant courses}

\section{Best placed to deliver training}

marketing, partly because they lack the staff with the required knowledge and expertise, partly because academic syllabi must go through protracted design, development and validation processes that stabilize a course for several years. Though they have some flexibility as to what to teach within course guidelines, the drive to economies of scale by universities (marketing modules are often taught to a hundred or more students) means that the focus is primarily on teachability. This includes ensuring that students study a number of academic papers with bearing on the subject. Some are out of date by the time they are published, partly because pure academic (ie, non-practitioner) journals tend (again with honourable exceptions) to publish research of little use to digital marketers (for example, studies of simple digital behaviour in invalid samples of respondents).

When taken as part of a wider marketing course at university, digital marketing teaching can do a lot to prepare students for jobs in the digital marketing world. Most universities now have a module or two on the subject in their undergraduate marketing or business degrees, with several universities offering full degrees in digital marketing. For practitioners, Masters-level courses are more relevant. In the United Kingdom, a few universities, such as Regents University with its new Masters in Digital Marketing and Analytics (on which I shall be teaching next semester), the IDM's partners London South Bank University's Masters in Digital Marketing and Southampton University's Masters courses in Digital Marketing (they also do one in Digital Analytics), have identified the need for a different approach, focusing on covering the most advanced practice and with a strong team of practitioners supporting the core teaching staff. Other leading players in the Masters market include Bedfordshire, De Montfort, Glasgow Caledonian, Hull, London Metropolitan, Newport and Portsmouth. My view is that, when universities teach courses that are developed with and/or validated by bodies such as the IDM, the situation is much better. Students can be assured of the practical relevance of the topics, combined with depth of understanding.

Academics focused on course content can lose touch with practical business requirements. One respondent looked at the syllabus of one of the courses mentioned above and felt that the inclusion of 'essay writing' was a case of 'losing the plot'. He felt that a more critical requirement was to get an argument and results across in a maximum of six pages of PowerPoint and 10 minutes (This is a polite version of his comment!).

\section{The role of the IDM}

This brings me to the role of professional institutes like the IDM. As the IDM is so closely in touch with the reality of business and can draw on a large number of practitioners who can also lecture (I hope), it is best placed to meet digital marketing training requirements. Those who take IDM courses not only emerge knowing things, but are able to plan and execute well. However, the IDM must stay in close touch with the market. Its in-house professional development for leading-edge 
装. Stone

\section{Conferences}

The web

\section{Suppliers not objective enough}

\section{Some consultants are great trainers}

customers - whether client- or agency-side - is central to its ability to provide the best training on its public diploma and certificate courses.

Conferences, generally over 1 or 2 days, are a really valuable way of transferring learning for those who need to be up-to-date with a wide range of management approaches, tools and techniques, whether to improve their own practice or to check that their practice is state-of-the-art. They also help practitioners to network. The most valuable source of learning for practitioners is usually other practitioners.

The web itself, with its many blogs, white papers and discussion groups, is also an invaluable source of learning. However, just as important is the creation of online courses, whether run asynchronously in a 'teach yourself' mode or synchronously with tutors using instructional software to address tens or even hundreds of students - such lectures can, of course, be recorded and used asynchronously. The UK's Open University (for which I teach economics) has been a leader in this area, showing the very high quality levels that can be reached. The IDM is also committed to this approach. It will be interesting to see whether the MOOC approach (Massive Open Online Courses) begins to have an impact here.

\section{But who are the trainers?}

So who is producing all the material? As I have become more deeply involved with the IDM, I have started to think about the question "who makes a good trainer?' I have come up with what may be a controversial answer - which is that people (like me?) who supply consultancy and other services may not be! That's because a good trainer should be reviewing all possible approaches to a subject and considering their value for trainees and client companies. Consultants and services providers tend to have a very different objective - to sell their own products. Sometimes they are too close to a subject, not able to perform the critical role of distancing themselves from particular recent experiences (I find that very difficult).

Before I am shouted down, I know that some of the very best trainers are consultants, because they combine really deep knowledge from recent assignments with a well-developed sense of how to apply ideas. They not only have the right competencies and case studies (including the ability to construct case studies to allow realistic role play), but also enthusiasm for the subject and the motivation to improve the professional lives of their trainees.

But not all do! It's one of the reasons why I've decided that my main focus for the next few years will be training and skills development, working closely with the IDM, rather than consultancy. In doing this, I am relieved to see the tough framework that the IDM imposes upon its consultant trainers to ensure that they deliver the right results for clients. It may be a bind planning a training course using these frameworks, but from the trainee's point of view, it is essential.

\section{The medium, the message and the people}

One of my respondents made this comment: 'Gone are the days of the classroom ... today we use networking events, conferences, classrooms, 


\section{Learning by leading}

\section{Training on the strategic agenda}

\author{
Integrated training not \\ available - Yet
}

in-house guru sessions and many more to build the knowledge base that we need. My insight and analytics teams have attended the many guru sessions our marketing department has run this year, with speakers from Google, Twitter, Amazon and other leaders, plus some good, old-fashioned brand agencies and geo-demographic data providers'. This echoed a point that I feel very strongly about - education is a mutual process, not only within companies, but between companies. It has to take the many forms that suit the many different players in the modern marketing eco-system. The medium and the message should be determined not just within a company, but in consultation with its marketing partners - agencies, affiliates, distributors, data suppliers, even systems suppliers.

As another respondent put it, "we are taking people on a digital journey, trying to embed digital at the heart of our work (being "digital first") and encountering what we interpret as pockets of resistance. Our view has been that being digital means cultural change and sometimes we are expecting people to just get it (transferring into the workplace skills and behaviours being learnt natively in their life outside of work, eg, using social media). What we have not done is roll out across the board formal training. We have guest speakers, share learnings and insight and create working groups and so on, all of which contribute to a "soft" learning agenda. But we are lacking when it comes to a harder, more formal learning agenda. There are two reasons for this. One is cost, the other is that we find that we are at the cutting edge ourselves in some areas. So who can we turn to learn from when we are learning by doing it first?'

As one of my respondents put it, 'training is also about businesses, teams, departments, suppliers talking more, discussing a key business challenge, prioritising, being clear on objectives, effectively projectmanaging through to a solution. In-house training, hosted/led by an external trainer can work well to draw out the hidden expertise that jointly or individually people have. This can complement targeted, pure off-site training courses. Sharing between companies by networking and creating opportunities to swap ideas is a great way of growing confidence in what you know as well as gaining new ideas.'

\section{Conclusions}

What is my conclusion from all this? Given the shortage of digital marketing skills (one of the best pieces of evidence for this is the Google Squared programme, aimed at familiarization with the digital agenda and training hundreds of young — and not so young — marketers in the basics of digital skills, using state-of-the-art, online training techniques and group case projects), I would put training on every strategic planning agenda (Yes, I do have a vested interest!).

However, it should not just be a box labelled 'training', but an agenda item that leads to an intelligent, insightful review of what kinds of training should be provided and how the training will work to attract and keep staff, where necessary in a framework of continuous professional development, especially for younger members of staff who are pretty good at finding alternative job offers. Perhaps it should not even be called digital 
marketing training, as most of the comments from those I circulated this article to emphasized the need for training that integrated offline and online topics. One senior manager commented that he was not aware of any such training and would send his people on it if it existed. A clear buying signal!

\section{Acknowledgement}

My thanks to the following people who commented: Amanda Arthur, Head of Data and Analytics, Proximity; Tom Breuer, VP data analytics, Cengage Learning and Editor, Journal of Marketing Analytics; Leslie Bruce, Head of Customer Insight, Nationwide Building Society; Mark Chipperfield, Head of Data Management, BBC; Paul de Laat, Group Customer Insight Director, John Lewis Partnership; Mark Evans, Marketing Director, Direct Line; David Hebden, Head of Marketing Science, Virgin Media; Paul Laughlin, Independent Consultant (formerly Head of Customer Insights, Insurance, Lloyds Banking Group); Nick Lines, Head of Customer Product Insight, Lloyds Banking Group; Andrew Lynn, Head of Data, UNICEF UK; Graeme McDermott, Head of Customer Data, AA; Jed Mole, European Marketing Director, Acxiom; Christine Olivier, Head of Learning Operations, Floream/Google Squared Online; Martin Squires, Head of Customer Insight, Boots; Sergio Vieira, Customer Insights Director, Lloyds Banking Group; Adam Williamson, Head of Marketing and Retail Effectiveness, British Airways; and Julia Wolny, Principal Fellow in Marketing, Southampton University. 